\begin{tabular}{|c|c|c|}
\hline GE & 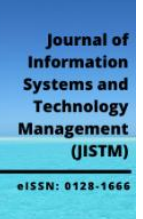 & $\begin{array}{c}\text { JOURNAL OF INFORMATION } \\
\text { SYSTEM AND TECHNOLOGY } \\
\text { MANAGEMENT (JISTM) } \\
\underline{w w w . j i s t m . c o m ~}\end{array}$ \\
\hline
\end{tabular}

\title{
IFC AND CITYGML SEMANTIC TRANSFORMATION FOR 3D GIS
}

\author{
Mohammed Jawaluddeen Sani ${ }^{1,2 *}$, Ivin Amri Musliman ${ }^{2}$, and Alias Abdul Rahman ${ }^{1}$ \\ 1 Department of Geoinformatics, Faculty of Built Environment and Surveying, Universiti Tecknologi Malaysia \\ (UTM) Johor, Malaysia \\ Email:mjsani71@gmail.com, alias.fksg@gmail.com \\ 2 Department of Surveying and Geoinformatics, School of Environmental Technology, Federal Polytechnic, Bauchi, \\ Bauchi State, Nigeria. \\ Email: mjsani71@gmail.com; ivinamri@utm.my \\ * Corresponding Author
}

\section{Article Info:}

\section{Article history:}

Received date: 01.10 .2021

Revised date: 01.11.2021

Accepted date: 20.11.2021

Published date: 01.12.2021

\section{To cite this document:}

Sani, M. J., Musliman, I. A., \& Abdul Rahman, A. (2021). IFC And CityGML Semantic Transformation For 3D GIS. Journal of Information System and Technology Management, 6 (24), 326-333.

DOI: $10.35631 / J I S T M .624030$

This work is licensed under CC BY 4.0

(1)(1)

\begin{abstract}
:
Building information modelling (BIM) and geographical information systems (GIS) domains immensely contribute to a digital representation of architectural and environmental bodies respectively. BIM is endorsed in order to enhance the Architecture Engineering and Construction (AEC) industry process to save time, cost and speed up the project, and more so, to minimise the frequent requests of information by the stakeholders within the industry. On the other hand, the Geographic Information System (GIS) has been increasingly used to generate detailed 3D data, geolocation and spatial analysis. Both BIM and GIS provide 3D data for the development of 3D city models, digital twin, smart city, AEC etc. However, there are significant diverse between the two in terms of their characteristics, scope of interest and focus that makes it difficult to easily be achieved. The amalgamation of the two worlds provides a clear picture of a built environment based on data (geometry and semantics) integration, which reinforces the enhancement of the three-dimensional (3D) applications in general into the digital world. This paper presents a methodology that semantically integrates the two worlds through their standards that is the Industry Foundation Classes (IFC) which is an open standard, selected because it is the typical free standard to exchange data in the BIM world and City Geography Markup Language (CityGML) is the most leading 3D city model standard in 3D GIS. This is carried out by performing a semantic mapping between the two standards, converting the encoding that the two standards use from STEP in IFC(BIM) to XML in CityGML (3D GIS), by providing a basic implementation created using Python to combine the above tasks.
\end{abstract}

Keywords:

Semantic Transfer, IFC, CityGML 


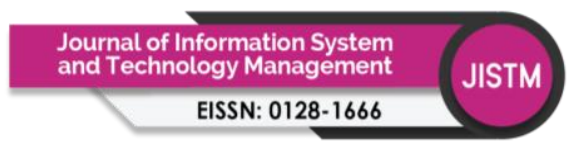

Volume 6 Issue 24 (December 2021) PP. 326-333 DOI: 10.35631/JISTM.624030

\section{Introduction}

In creating a new BIM project, architects and engineers go through different steps from creating a schematic model to creating a digital representation of the building in BIM (Eastman et al. 2008; Azhar et al., 2012). Throughout these steps, GIS can integrate a layer of geospatial context into the BIM model, which is beneficial because the two domains operate on different scale levels. On the one hand, GIS provides information at the city level, and on the other hand, BIM the physical structure is design at an object level, such as sketching and placing any building elements (Wall, Door, Window etc.)(Arcuri et al. 2020). In comparison, BIM data applies to designing and building a specific shape or structure. By adding GIS data, the BIM model can be managed within a larger and smarter landscape. For example, a building will be connected to a parcel of land, utilities, and roads ("GIS and BIM integration will transform infrastructure design,”)(D’Amico et al. 2020). Hence, the interoperability of IFC and CityGML is becoming more important day by day despite the differences in their modelling 3D applications such as in the AEC industry.

Currently, the above-mentioned BIM integration within GIS is challenging, due to the difference in data formats used for both, hence the lack of interoperability between the two (Kang and Hong 2018). The study aims to bridge the gap by providing a method to transform common data models from BIM to GIS by using their strongest parts that are IFC and CityGML data formats respectively for an effective flow of information from BIM to GIS and vice versa. Therefore, the need for IFC and CityGML semantic transformation. The rest of the paper is structured as follows: Section 2 previous work on the IFC and CityGML semantic integration. Section 3 present the research methodology. Section 4 present the result(s) of the semantic integration. Section 5 is the conclusion and recommendation for future work.

\section{Related Work}

The result of integrating BIM and GIS can be used to carry out various analyses but the integration of the two domains through the standards (IFC and CityGML) is primarily for the purpose of information sharing. The multitude of information acquired from the BIM model could be deployed into GIS for 3D spatial query and spatial analysis(Li et al. 2019). Different authors focused more on the unidirectional approach where the integration is mainly from BIM to GIS. Floros et al., (2018) investigate a unidirectional conversion from BIM to GIS elaborating further on the differences of the geometries between the two standards and especially on the issues that arise for the conversion of space geometries and boundaries. Isikdag and Zlatanova (2009) propose a unidirectional framework for generating CityGML models using BIM in two stages: semantic mapping and geometry simplification. Nagel et al. (2009) propose reconstruction methods for 3D models by splitting the process into two stages: (i) conversion of the 3D model to CityGML based on specific spatial-semantic principles, (ii) CityGML to IFC. The results determine significant challenges in handling geometry between the two standards, since CityGML supports exclusively boundary-representation (B-rep), while IFC is more flexible. El-Mekawy et al. (2012) analyzes the semantic mapping between IFC and CityGML and concludes that there are noticeable differences with the geometric and semantic structure of CityGML. Donkers et al. (2016) present an automatic process for converting an IFC model to a LoD3 CityGML that is evolved in three stages: semantic filtering and mapping, geometric transformations, and geometric and semantic refinements. The generated models contain only the semantic information that is relevant to the CityGML standard, thus the additional IFC semantic properties are discarded. The necessity of expanding 
the conversion not only to CityGML LoD4 models but also to other city objects such as tunnels, bridges and roads is noted. Göçer et al. (2016) demonstrates the importance of generalizing IFC models, aiming to reduce geometric and semantic redundancy and facilitate the extraction of a LoD1-3 representation, while the need for LoD4 models remains. Furthermore, questions arise about the efficient mapping not only of geometry but also semantics. The integration of BIM and GIS, on the other hand, is not straightforward. This is primarily due to the differences between BIM and GIS, which are typically formulated based on their coordinate system, spatial scale, level of complexity and details in real-world modelling, geometry representation method, time scale, storage and access methods, as well as semantic mismatches between them. (Amirebrahimi et al. 2016;El-Mekawy and Östman 2010) Among all the differences stated we propose an algorithm to address the challenge of semantic information mismatch due to the conversion.

From previous work, several authors concentrated more on the unidirectional approach which leads to semantic loss. To solve the problem of missing information because of the semantic integration of BIM and GIS, there is an apparent need for a bidirectional approach. In this paper we created an integrated model to serve as an intermediate model between IFC and CityGML, the methodology is presented in the following section.

\section{Semantic Transfer}

An obvious problem in data-level integration is that the semantic data may not be fully transformed, mainly due to semantic mismatches between the two domains. Most solutions for dealing with semantic losses are exclusively based on the CityGML standard.

Semantic mismatches between BIM and GIS mean (1) that there are different definitions for the same object. For example, a Door in IFC is defined as "IfcDoor" Roof in IFC is "IfcRoof" while in CityGML, is referred to as Door and Roof or (2) that one defines a component while the other does not. For instance, IFC defines beam, column, stair, and so on, while CityGML does not, and generalises these as "BuildingInstallation" (Donkers et al., 2016; Noardo et al. 2020). This has resulted in problems in some applications. For example, when a 3D city model by integrating BIM and GIS given more details with regards to the maximum level of details i.e., LOD 4 in both BIM and GIS which is the interior of the buildings which requires the furniture, ceiling, the stairs, ceiling etc. lack of corresponding matching between the entities of IFC and CityGML makes it so difficult to achieve full interoperability or integration between the two worlds that lead to semantic data loss. Therefore, the need for semantic mapping as shown in figure 1.

The transfer of semantic information is needed to achieve BIM and GIS integration at the semantic level, this is the objective of this paper. The integration factors of semantic data such as level of difficulty to achieve which is high, the richness of information which is also high and finally the purpose of the semantic transfer mainly is for visualization and analysis, therefore, the integration of BIM and GIS at the semantic level is so complicated as a result of a multitude of information attributed to BIM compared to GIS with less information. 


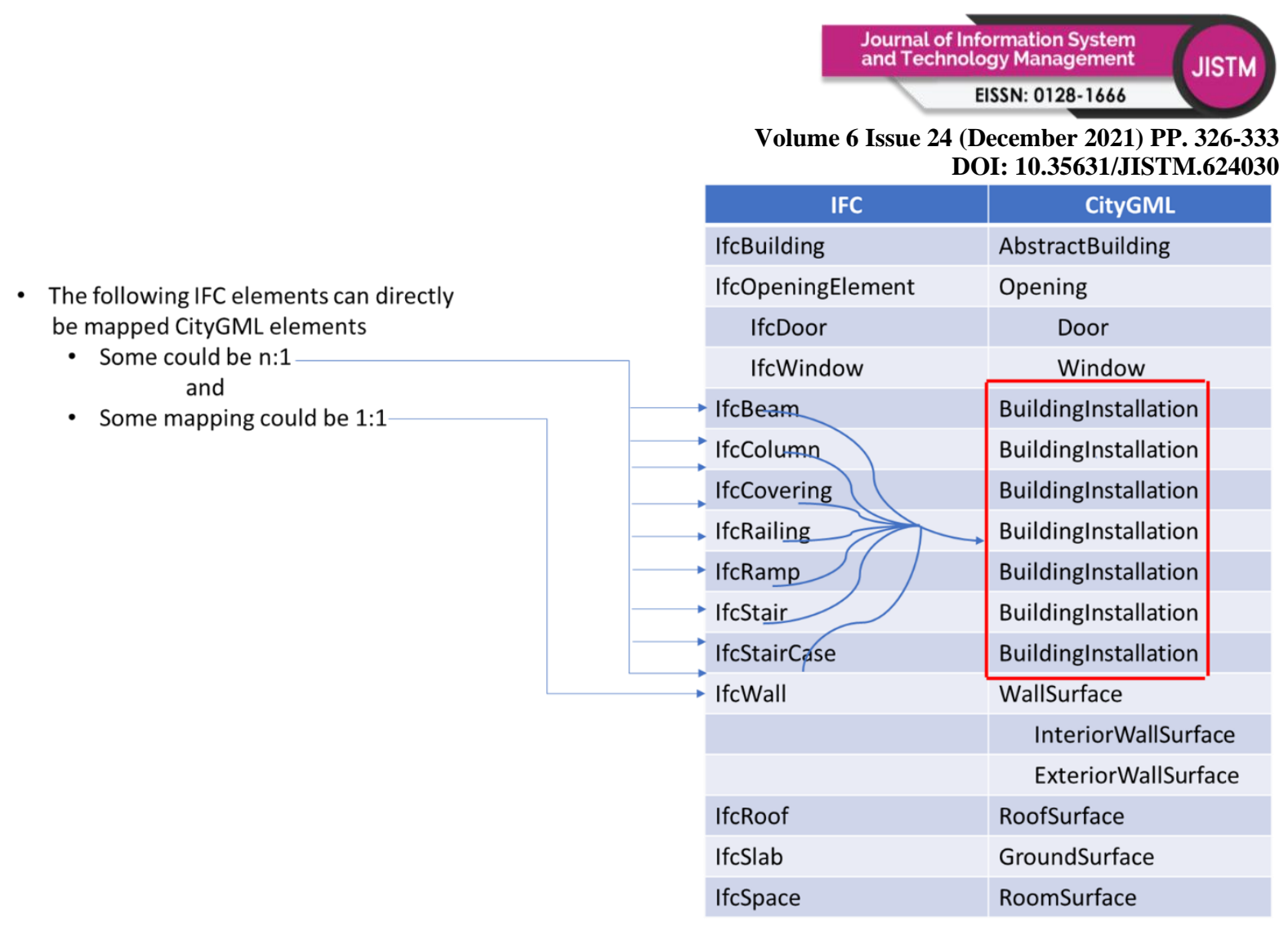

Figure 1: Semantic Mapping of IFC and CityGML Entities

\section{Methodology}

The concept proposed in this paper is expected to assume a practical approach, which minimizes this shortcoming by using IFC and CityGML schemas in their practically original forms into an integrated data model, which is referred to as Integrated BIM and GIS data model (IFC and CityGML Model). This is through the creation of a new and separate schema apart from BIM and GIS models. This model serves as an intermediate model for the transfer of information from one model to another i.e., IFC to CityGML and vice versa. In this paper, we now present three models and all three schemas. The proposed integrated model stored data from both IFC and CityGML in order to enable the transfer of semantic information from BIM to GIS and vice versa. Finally, three models which include BIM, GIS and Integrated BIM and GIS model are employed in one database.

A database is created to accommodate both the three models mentioned above. The major advantage of creating the third model is to eliminate data redundancy. Each object is saved in the database once but can be seen using CityGML and IFC views. From the point of view of BIM and GIS applications, the integrated data model, is invisible. Each of these applications read data using the appropriate IFC or CityGML model.

The source building model was developed in BIM using Revit in LOD4 and converted to an IFC file still in LOD4. Geometry transformation was conducted by developing a code from IFC to CityGML and was viewed in FZK viewer in LOD3 as shown in figure 3. The semantic transfer from IFC to CityGML was carried out using the created from the three models as shown in figure 2. 


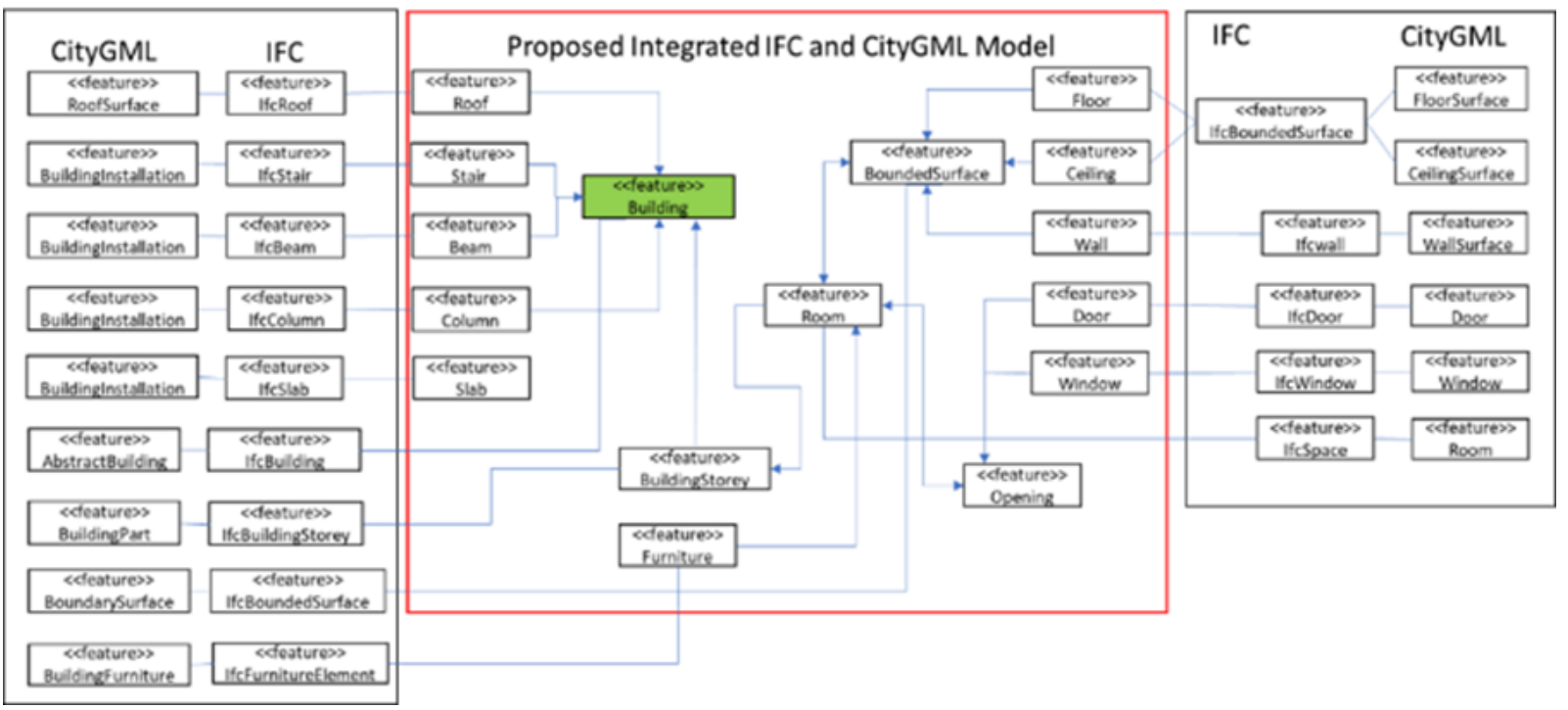

Figure 2: Proposed Integration IFC and CityGML Model (IBIGM) for Semantic Transfer

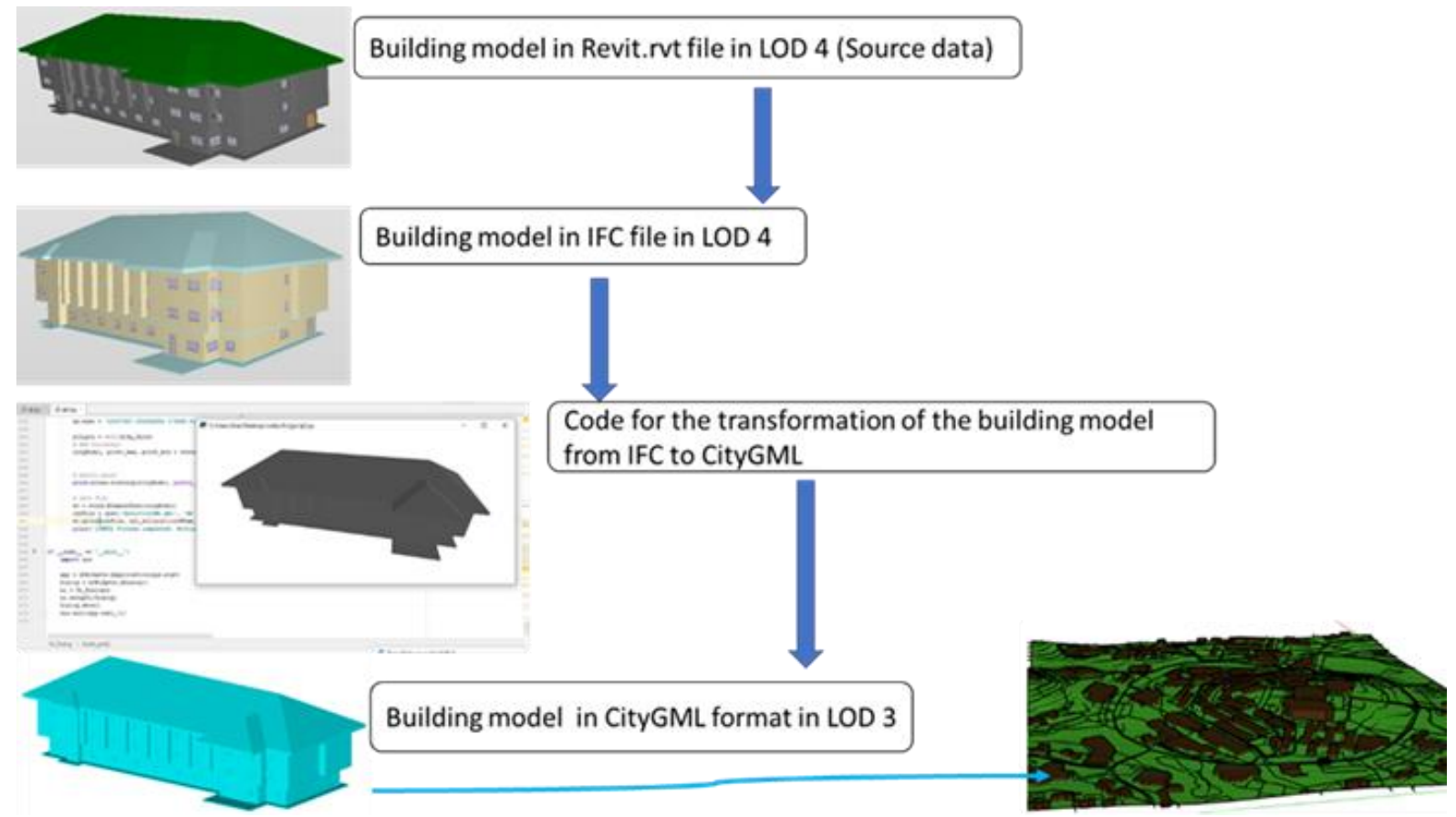

Figure 3: Converted Model 


\section{Results}

The result of the transferred semantic information from IFC to CityML is shown in table 2 based on the IFC entities in table 1

Table 2: IFC to CityGML Mapping

\begin{tabular}{ll}
\multicolumn{1}{c}{ IFC } & \multicolumn{1}{c}{ CityGML } \\
\hline IfcBeam & BuildingInstallation \\
IfcColumn & BuildingInstallation \\
IfcStair & BuildingInstallation \\
IfcStairFlight & BuildingInstallation \\
IfcWall & WallSurface \\
& \multicolumn{1}{c}{ InteriorWallSurfce } \\
& ExteriorWallSurface \\
IfcRoof & RoofSurface \\
IfcSlab & GroundSurface \\
IfcSpace & RoomSurface \\
IfcOpening & Opening \\
\multicolumn{1}{c}{ IfcDoor } & \multicolumn{1}{c}{ Door } \\
IfcWindow & Window \\
IfcBuilding & AbstractBuilding \\
IfcSite & Site \\
IfcSpace & Room \\
IfcFurniture & Furniture \\
IfcStorey & BuildingStorey \\
\hline
\end{tabular}

Table 2: IFC Entities for CityGML

\begin{tabular}{|c|c|c|c|c|c|}
\hline IFC & $\begin{array}{c}\text { \# of } \\
\text { Elements }\end{array}$ & IBIGM & $\begin{array}{c}\text { \# of } \\
\text { Elements }\end{array}$ & CityGML & $\begin{array}{c}\text { \# of } \\
\text { Elements }\end{array}$ \\
\hline \multirow[t]{3}{*}{ IfcWall } & 315 & WallSurface & 630 & WallSurface & \\
\hline & & & & InteriorWallSurface & 315 \\
\hline & & & & ExteriorWallSurface & 315 \\
\hline IfcRoof & & Roof & & RoofSurface & \\
\hline IfcSlab & 43 & GroundSurface & 43 & GroundSurface & 43 \\
\hline \multirow[t]{2}{*}{ IfcOpening } & & Opening & & Opening & \\
\hline & 73 & Window & 73 & Window & 73 \\
\hline $\begin{array}{l}\text { IfcWindow } \\
\text { IfcDoor }\end{array}$ & 103 & Door & 103 & Door & 103 \\
\hline IfcBeam & & Beam & & BuildingInstation & \\
\hline IfcColumn & & Column & & BuildingInstation & \\
\hline IfcStair & 4 & Stair & 4 & BuildingInstation & 4 \\
\hline IfcStairFlight & 8 & StairCase & 8 & BuildingInstation & 8 \\
\hline IfcStorey & 4 & BuildingStorey & 4 & BuildingStorey & 4 \\
\hline IfcFurniture & 272 & Furniture & Missing & Furniture & Missing \\
\hline IfcSpace & 42 & Room & 42 & Room & 42 \\
\hline IfcBuilding & 1 & Building & 1 & Building & 1 \\
\hline IfcSite & 1 & Site & 1 & Site & 1 \\
\hline
\end{tabular}




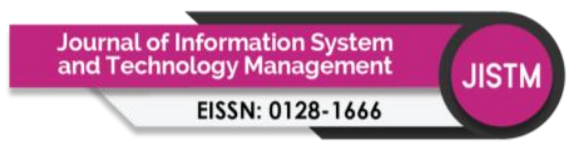

Volume 6 Issue 24 (December 2021) PP. 326-333 DOI: 10.35631/JISTM.624030

\section{Conclusion}

This paper proposed an Integrated IFC and CityGML model which is an intermediate model for the semantic transfer of IFC to Semantic information. The research is based on the integration of BIM and GIS at the data level focusing on the semantic information, the geometry information was presented in our previous research. The geometry is based on coordinates transformation from local cartesian coordinates system in BIM to world coordinates system in GIS. The semantic transfer or transformation presented in this paper is based on the semantic mapping of IFC and CityGML. The mapping of the entities was conducted by developing an intermediate IFC and CityGML integration model as shown in figure 2. Even though the semantic loss as a result of transformation or transfer is unavoidable, our approach minimised the sematic loss. The results of our research were compared with other integration methods that were mainly unidirectional approach based.

\section{References}

Amirebrahimi, Sam, Abbas Rajabifard, Priyan Mendis, and Tuan Ngo. 2016. "A BIM-GIS Integration Method in Support of the Assessment and 3D Visualisation of Flood Damage to a Building." Journal of Spatial Science 61(2):317-50.

Arcuri, Natale, Manuela De Ruggiero, Francesca Salvo, and Raffaele Zinno. 2020. "Automated Valuation Methods through the Cost Approach in a BIM and GIS Integration Framework for Smart City Appraisals." Sustainability (Switzerland) 12(18):1-16.

Azhar, Salman, Malik Khalfan, and Tayyab Maqsood. 2012. "Building Information Modeling (BIM): Now and Beyond." Australasian Journal of Construction Economics and Building 12(4):15-28.

D’Amico, Fabrizio, Alessandro Calvi, Eleonora Schiattarella, Mauro Di Prete, and Valerio Veraldi. 2020. "BIM and GIS Data Integration: A Novel Approach of Technical/Environmental Decision-Making Process in Transport Infrastructure Design." Transportation Research Procedia 45:803-10.

Donkers, Sjors, Hugo Ledoux, Junqiao Zhao, and Jantien Stoter. 2016. “Automatic Conversion of IFC Datasets to Geometrically and Semantically Correct CityGML LOD3 Buildings." Transactions in GIS 20(4):547-69.

Eastman, Chuck, Paul Teicholz, Rafael Sacks, and Kathleen Liston. 2008. BIM Handbook on A Guide to Building Information Modeling for Owners, Managers, Designers, Engineers, and Contractors.

El-Mekawy, M. and Anders Östman. 2010. "Semantic Mapping: An Ontology Engineering Method for Integrating Building Models in IFC and CITYGML." Proceedings of the 3rd ISDE Digital Earth Summit 1-11.

El-Mekawy, Mohamed, Anders Östman, and Ihab Hijazi. 2012. "A Unified Building Model for 3D Urban GIS." ISPRS International Journal of Geo-Information 1(3):120-45.

Floros, G. S., C. Ellul, and E. Dimopoulou. 2018. "Investigating Interoperability Capabilities between IFC and CityGML LoD 4 - Retaining Semantic Information." International Archives of the Photogrammetry, Remote Sensing and Spatial Information Sciences ISPRS Archives 42(4/W10):33-40.

Göçer, Özgür, Ying Hua, and Kenan Göçer. 2016. "A BIM-GIS Integrated Pre-Retrofit Model for Building Data Mapping.” Building Simulation 9(5):513-27.

Isikdag, Umit and Sisi Zlatanova. 2009. 3D Geo-Information Sciences. edited by J. Lee and S. Zlatanova. Berlin, Heidelberg: Springer Berlin Heidelberg. 
Volume 6 Issue 24 (December 2021) PP. 326-333 DOI: 10.35631/JISTM.624030

Kang, Tae Wook and Chang Hee Hong. 2018. "IFC-CityGML LOD Mapping Automation Using Multiprocessing-Based Screen-Buffer Scanning Including Mapping Rule." KSCE Journal of Civil Engineering 22(2):373-83.

Li, W., S. Zlatanova, J. J. Yan, A. Diakite, and M. Aleksandrov. 2019. "A Geo-Database Solution for the Management and Analysis of Building Model with Multi-Source Data Fusion." International Archives of the Photogrammetry, Remote Sensing and Spatial Information Sciences - ISPRS Archives 42(4/W20):55-63.

Nagel, Claus, Alexandra Stadler, and Thomas H. Kolbe. 2009. "Conceptual Requirements for the Automatic Reconstruction of Building Information Models from Uninterpreted 3D Models." Proceedings of the International Archives of Photogrammetry, Remote Sensing and Spatial Information Sciences 46-53.

Noardo, Francesca, Lars Harrie, Ken Arroyo Ohori, Filip Biljecki, Claire Ellul, Thomas Krijnen, Helen Eriksson, Dogus Guler, Dean Hintz, Mojgan A. Jadidi, Maria Pla, Santi Sanchez, Ville Pekka Soini, Rudi Stouffs, Jernej Tekavec, and Jantien Stoter. 2020. "Tools for BIM-GIS Integration (IFC Georeferencing and Conversions): Results from the GeoBIM Benchmark 2019." ISPRS International Journal of Geo-Information 9(9):1-35. 